\title{
ФОРМИРОВАНИЕ КОНВЕРГЕНТНОЙ ТИПОЛОГИИ СТРУКТУРНЫХ СДВИГОВ В ЭКОНОМИКЕ
}

\author{
(c) 2019 Таран Екатерина Александровна \\ старший преподаватель, Школа инженерного предпринимательства \\ Национальный исследовательский Томский политехнический университет, Россия, Томск \\ E-mail: ektaran@tpu.ru
}

В статье рассмотрены факторы, критерии и составляющие конвергентной типологии структурных сдвигов в экономике, которые выступают начальной и конечной точкой ее технологической и социально-экономической модернизации, выхода на анти-рецессивный тренд по мере развертывания глобального процесса смены технологических укладов. Систематизирована связь между разноуровневыми феноменами технологической, структурной и экономической конвергенции, объединяемыми понятием конвергентного структурного сдвига. Раскрыто антагонистическая сущность структурной дивергенции и дивергентного структурного сдвига, в которых результирует дегенеративный тип структурной трансформации, формирующийся в ходе деиндустриализации реформируемой российской экономики.

Ключевые слова: структурный сдвиг, экономическая конвергенция, структурная конвергенция, структурная дивергенция, типология.

В условиях нарастания технологического отставания российской экономики, деградации в ней поздне-промышленного (пятого) технологического уклада, перспективы нового глобального технологического сдвига несут опасность окончательного разрыва с мировыми центрами инновационных компетенций, с более глубокими макроэкономическими, воспроизводственными, социальными последствиями, чем деиндустриализация начального этапа рыночных реформ. Это актуализирует научный анализ структурных сдвигов, индуцированных углублением технологической конвергенции, трансформации воспроизводства.

Структурные сдвиги, радикально меняющие макро- и мезоэкономические пропорции, инициируют тренды сближения или отдаления национальной экономики от развитых рыночных систем, родственных феноменам экономической конвергенции и дивергенции. Однако к настоящему моменту критериями последних являются общие показатели экономической динамики (ВВП на душу населения, дефицит бюджета, темпы инфляции и волатильность национальной валюты, объем государственного долга (Маастрихтские критерии конвергенции)), которые отражают распределение, но не структуру производства ВВП.

В распространенных к настоящему моменту теоретических подходах к исследованию эконо- мической конвергенции ее сущность раскрывается через связь процессов вестернизации, экспансии транснациональных корпораций, эффект «низкого старта» при ускорении вовлечения развивающихся стран в мировую систему финансовых, производственных, торговых отношений. В данной статье показано, как раскрытие критериев и факторов структурной конвергенции позволяет сформировать типологию структурных сдвигов, отражающую процессы сближения экономик промышленно развитых стран по своим структурным пропорциям, закладывающим основу доминантных трендов макроэкономической динамики.

В процессе исследования был использован комплекс методов современной экономической науки, включающий системный, причинно-следственный логический анализ, позволяющих выделить, структурировать и соотнести основные факторы и критерии конвергентных и дивергентных структурных сдвигов, а также дать их типологическую идентификацию.

Структура системы национальной экономики обладает значительной инерцией, обусловленной объективным характером межэлементных связей внутри системы. Поэтому структурные сдвиги отражают реализацию определенного потенциала в развитии экономических отношений, определяемого критическими значениями диспропорций в вос- 
производственной системе, в распределении и перераспределении ресурсов и произведенных благ. При этом общий ход структурных сдвигов детерминирован научно-техническим прогрессом, который играет противоречивую роль - будучи во многом экзогенным явлением по отношению к развитию экономических отношений, он, тем не менее, инициирует глубокие эндогенные изменения в системе воспроизводства, меняя сложившиеся механизмы инвестирования и накопления капитала, вовлечения природных и интеллектуальных ресурсов в производство, модифицируя субъектов экономических отношений и связи между ними.

Поэтому научно-технический прогресс, безусловно, способен вызвать структурные диспропорции в экономике, достаточные для преодоления структурной инерции, и вызвать структурные сдвиги (что описывает теория технологических укладов, развиваемая на дореформенном этапе Д. С. Львовым [5], а впоследствии С.Ю. Глазьевым [2], Ю.В. Яковцом [11] и др.).

При этом не менее важно другое - научно-технический прогресс задает долгосрочный вектор структурных изменений в экономике на глобальном уровне, который определяет широту распространения процесса смены общественных потребностей (эндогенного по своей сути) и характер мировых экономических явлений (создание и разрушение международных союзов, глобализацию и анти-глобализацию, и пр.). Все это вполне укладывается в методологию инерционности структуры экономики, из которой следуют противоречия разнонаправленных [3], локальных и глобальных [1], экзогенных и эндогенных структурных сдвигов [4].

Из этого мы делаем два вывода. Во-первых, поскольку структурные сдвиги связаны с развитием экономических отношений, которые определяют распределение факторов производства, кругооборот ресурсов, доходов и сбережений, то они представляют собой комплекс изменений во всех видах структуры экономики, которые, начинаясь в процессе модификации экономических отношений, в совокупности важнейших институтов, в воспроизводственной системе, послужат толчком для качественного скачка основных макроэкономических (норма накопления, инвестиционный и технологический мультипликаторы, индуцированные и автономные инвестиции и пр.) и мезоэкономических (межотраслевое распределение инвестиций и
ВВП, инновационная активность фирм, уровень конкуренции, социальные группы и пр.) пропорций. При этом завершенный сдвиг, формирующий новое качество экономики, характеризуется меньшей энтропией, чем изменения в отдельных видах структуры (отраслевой, рыночной, форм собственности, кластерной и пр.). Напротив, частичные структурные изменения вызывают рост энтропии, внося возмущение в систему интересов субъектов экономики, меняя сложившиеся связи между ними по распределению ресурсов, продукта, доходов. В результате вмешательства государства, порождающего частичные, несистемные структурные изменения, возникают новые экстерналии, усиливающие энтропию.

Во-вторых, комплексные полномасштабные изменения структуры национальной экономики качественно приближают или отдаляют ее от наиболее технологически передовых развитых рыночных систем, то есть могут считаться составляющими общемировых процессов экономической конвергенции [12] и дивергенции [8]. Последние характеризуют единый процесс экономического развития диалектически - через свойственному любому объективному феномену разделению на части, обладающие своими собственными формами, и объединению в принципиально новое целое [9].

Философская интерпретация связи конвергентных и дивергентных тенденций внутри движения структуры сложных систем такова. Качественные различия внутриструктурных элементов при определенных условиях развития системы приводят к их обособлению; структура приобретает новую дивергентную форму, по-иному адаптируясь к внешней среде, и вся система функционирует иначе. Однако, по мере накапливания условий качественного скачка в развитии системы, ее отдельные стороны начинают сближение благодаря формированию новых элементов с общими свойствами. В частности, инновационное развитие национальных экономик (открытых, проницаемых систем) обеспечивает их конвергентное сближение по отдельным макроэкономическим показателям динамики ВВП, размеру подушевого ВВП.

Несмотря на многогранную трактовку конвергенции и дивергенции сложных систем (статические и динамические, пространственные и пространственно-временные, формальные и схематические системы [7], мы ориентируемся 
на их главное свойство - типологизация однородных систем по качественным отличиям в структуре, которые формируют как принципиально разные, так и сходные признаки в развитии этих систем.

Вместе с тем ясно, что как конвергентные, так и дивергентные явления внутри структуры экономики означают качественный скачок в ее преобразовании, поскольку они создают ее общности и различия со структурой других экономических систем. Одновременно структура экономики в процессе дивергенции или конвергенции наращивает отличия со своим прежним состоянием. Поэтому можно утверждать, что конвергенция и дивергенция есть типы структурного сдвига, которые отражают его сущность, а также то влияние, которое оказывают радикальные изменения структуры на макроэкономическую динамику.

К настоящему моменту критерии конвергенции, применительно к структуре экономики, исследованы недостаточно. В качестве основного критерия широко используется ВВП на душу населения, который характеризует распределение валового внутреннего продукт (бета-, сигма-, условная конвергенция [10], но не его создание (структуру экономики). Также следует выделить т.н. Маастрихтские критерии конвергенции (1992 г.) - показатели финансового сектора экономики стран Европы, вступавших в еврозону (дефицит бюджета не более 3\% от ВВП или профицит; стабильность национальной валюты, низкий уровень инфляции и процентов по гособлигациям, независимость центробанка от правительства) [13]. Несмотря на то, что данные критерии отражают состояние государственных финансов, они также характеризуют перераспределительные процессы, но не структуру создания национального продукта и воспроизводственную систему.

Основываясь на данном выводе, мы даем следующее уточняющее определение структурной конвергенции - как процесса накапливания факторов структурного сдвига в экономике, концентрирующих в себе эффективное внедрение последних достижений научно-технического прогресса, в комплексе необходимыми для этого институциональными, воспроизводственными, рыночно-конкурентными, социальными условиями, успешно реализуемыми в технологически передовых странах развитой рыночной экономики. В плане экономической динамики структурная конвергенция является первичной по отношению к сходству темпов экономического роста, поскольку сближает технологически прогрессирующие страны по общим фазам циклов.

К свойствам структурной конвергенции мы относим следующие:

1. Применимость в качестве методологического инструмента к анализу экономики стран с близкими характеристиками вовлечения факторов производства, главным образом, высоко-индустриализованных технологически передовых стран, в которых рост отдачи от капитала, беспрецедентная информатизация и технологическая конвергенция создают условия для нового структурного сдвига, ожидаемого к концу 2020-х гг.

2. Определяющая роль отдачи от факторов производства - капитала и технологий (т.е. интеллектуальной ренты), которая значительно опережает отдачу от использования фактора земли в виде природной ренты. Поэтому к тем странам, в которых данное опережение образует устойчивый тренд, применимо понятие структурной конвергенции как ключевого макроэкономического тренда, с характерным развитием современных институтов рынка и его регулирования государством.

3. Антагонистичность процессов снижения как предельной отдачи от капитала, так и предельной производительности труда в большинстве секторов российской экономики [6] феномену структурной конвергенции. В пользу этого свидетельствует и радикализующийся негативный отрыв экономики России по показателям подушевого ВВП, неравенства доходов, доле инновационно активных предприятий, интенсивности внедрения инноваций, качеству жизни от развитых стран. Это характеризует изменения в структуре российской экономике как дивергентные.

Экономическая дивергенция (от лат. diverge «расхождение») может быть определена как процесс, противоположный по сути экономической конвергенции, то есть, с одной стороны, усиление разрывов между развитыми и развивающимися странами в ключевых макроэкономических показателях, с другой - расхождение в основных структурных пропорциях.

Связь экономической дивергенции и структурного сдвига возникает в случае, если последний имеет деиндустриальный, дегенеративный 
характер, в результате чего такие структурные элементы, как неэффективные институты, монопольные госкорпорации, негативные воспроизводственные, отраслевые, социальные диспропорции образуют радикальные отличия экономики страны от технологически развитых рыночных систем, усиливают инерционность структурных проблем.

Если сближение темпов экономического роста вызвано преимущественно внешними факторами (рост мировых цен на основные статьи экспорта, приток иностранного спекулятивного капитала), то внутри самой структуры экономики будут нарастать отличия от технологически передовых, лидирующих стран. В конечном итоге эти структурные отличия будут обособляться, вызвав структурный сдвиг, который сформирует примитивную модель воспроизводства. В такой системе взаимной обусловленности внешних и внутренних факторов структурного сдвига экономическая конвергенция переходит в дивергенцию, усиливая структурные различия и лишая возможностей будущего сближения макроэкономических показателей с лидирующими странами.

Таким образом, структурная дивергенция связана с выделением в самостоятельный тренд таких процессов, как сокращение автономных инвестиций и сохранение низкой нормы накопления, старение средств производства, монополизация и рост государственных инвестиций в промышленности с низкой эффективностью, рост доли убыточных фирм, сокращение несырьевого экспорта, критическое падение инновационной активности, рост доли бедного населения.

Комплекс критериев конвергентной типологизации структурных сдвигов включает в себя следующие:

1. Критерии воспроизводства (автономные инвестиции, норма накопления, состояние основного капитала, возможность ускорения амортизации), которые отражают перспективы технологической модернизации промышленности и ускорения роста ВВП за счет повышения производительности труда.

2. Критерии инновационной восприимчивости экономики (интенсивность коммерциализации изобретений, трансфера инноваций), отражающие ее технологическую идентичность.

3. Инвестиционно-диверсификационные критерии, характеризующие отраслевую, техно- логическую, экспорто-ориентационную структуру инвестиций, в том числе иностранных, и устанавливающие планку технологической модернизации национальной экономики до уровня наиболее развитых государств.

4. Рыночно-предпринимательские критерии, позволяющие оценить степень развития инновационного бизнеса в реальном секторе и качество его связей с сциентарным сектором экономики, и отражающие пропорции государственных и частных инновационно-ориентированных инвестиций, состояние инновационно-технологической и инновационно-предпринимательской инфраструктуры.

5. Социально-структурные критерии, перспективные для использования в оценке влияния роста факторной эффективности труда в экономики на ее структурные сдвиги, и связанные с качественными и количественными характеристиками рабочей силы в сфере фундаментальных исследований, инновационных разработок и производств.

6. Институциональные критерии, которые характеризуют исходные предпосылки развития экономических отношений, формирующего потенциал структурного сдвига - нормы и правила в системе национального воспроизводства,- такие как эффективность фискальных стимулов инноваций, госгарантий и инновационно-импортозамещающих субсидий, ГЧП в высокотехнологичной сфере.

Наряду с перечисленными выше критериями, связь структурных сдвигов с конвергенций и дивергенцией в экономике определяется их факторами, комплекс которых включает мобильность факторов производства, диффузию инноваций, инновационное предпринимательство, социальное благополучие, реакцию на внешние шоки и импортозамещение, структурную политику.

Действие данных факторов включает внутреннюю и международную мобильность высокоинтеллектуального труда и инновационно-предпринимательского капитала, вовлечение технологической конвергенции в расширение национального воспроизводства, рост инновационно-инвестиционной привлекательности экономики, элитаризацию высокоинтеллектуальных социальных групп, институциализацию государственного регулирования мобильности факторов производства, реакцию фирм и государства на повышение волатильно- 
сти мирового рынка сырья, готового продукта и факторов производства.

Приняв за основу данные критерии и факторы связи структурных сдвигов в национальной экономике с более высокоуровневыми процессами - экономической конвергенцией и дивергенцией, конвергентную типологию структурных сдвигов можно представить в следующим виде:

А) Конвергентный структурный сдвиг, который инициирует конвергенцию экономики с характерным приближением ее структуры к наиболее развитым странам, прежде всего, по воспроизводственным (использование труда и капитала, накоплению и потреблению), технологическим и отраслевым, социальным пропорциям, а также по устойчивости макроэкономической динамики. Именно конвергентный структурный сдвиг вследствие своей необратимости сможет создать условия долгосрочного позитивного макроэкономического тренда.

Б) Дивергентный структурный сдвиг, как антагонистически противоположный конвергентному, означает отдаление структуры экономики по воспроизводственным, отраслевым, инновационно-технологическим, социальным пропорциям от технологически передовых стран с развитой рыночной экономики. Характеристикой дивергентного сдвига является также неустойчивость экономического роста, наличие продолжительной рецессии, нарастание дегенеративных структурных изменений в сравнении с новым глобальным трендом структуро-образования, связанным с ускорением трансфера технологий и их конвергенцией.

В) Квази-конвергентный структурный сдвиг представляет собой разновидность дивергентного сдвига, удовлетворяющего некоторым критериям экономической конвергенции - главным образом, росту подушевого ВВП, укреплению курсов валют, увеличению частного потребления и сбережений быстрыми темпами. Коренное отличие квизи-конвергентного сдвига заключается в сближении показателей доходов, сбережения и потребления с технологически передовыми странами, при сохранении и углублении структурных диспропорций. Это обусловлено экстенсивным экономическим ростом - следствием благоприятной конъюнктуры мирового рынка сырья и расширению его добычи, эффекта «низкого старта» для сырьевых экономик слаборазвитых стран с крайне низки- ми доходами и подушевым ВВП. При этом институты рынка, в том числе важнейшие - права собственности, меры структурной политики,остаются неразвитыми, препятствуя конвергентным преобразованиям структуры технологий, отраслевого распределения инвестиций, социальных групп и т.п.

В реформируемой российской экономике структурные сдвиги носят дивергентный характер, при котором экзогенно-обусловленная квази-конвергенция сменяется дивергенцией вследствие накапливания эндогенно-индуцированных расхождений в тенденциях изменения основных структурных пропорций, как с передовыми, так и технологически догоняющими странами. В результате ухудшаются воспроизводственные, инновационно-технологические, рыночно-отраслевые, социальные условия новых структурных элементов, индуцированных технологической конвергенцией. Применительно к структуре российской экономики, переход квази-конвергентного структурного сдвига к дивергентному сопровождается сокращением потенциала позитивного структурного сдвига и усилением структурной инерцией, ее конверсией в структурный кризис. В итоге усиливается опасность того, что структура российской экономики будет неспособна воссоздать механизмы трансфера и диффузии новых технологий, и ее социально-экономическая дивергенция примет характер деградации.

Представленная конвергентная типология структурных сдвигов в экономике позволяет определить потенциал ее ускоренного инновационного развития до уровня технологически передовых стран. В основу данной типологии структурных сдвигов положены их типы (конвергентный, квази-конвергентный и дивергентный), критерии (воспроизводственные, восприимчивости экономики к инновациям, диверсификации инвестиций, рыночно-предпринимательские, социальные, институциональные) и факторы (мобильность факторов производства, диффузия инноваций, инновационное предпринимательство, социальное благополучие, структурная политика, реакция на внешние шоки и импортозамещение).

Процесс усиления факторов структурного сдвига в экономике сближающих ее макроэкономические пропорции с развитыми странами, концентрирующих в себе эффективную коммерциализацию прорывных инноваций, создание 
ее институциональных, воспроизводственных, га структурная конвергенция может перейти в рыночно-конкурентных, социальных условий, дивергенцию, усиливая структурные различия получил название структурной конвергенции. В и сдерживая тренд сближения макроэкономичетакой системе взаимной обусловленности внеш- ских показателей с лидирующими странами. них и внутренних факторов структурного сдви-

\section{Библиографический список}

1. Гасанов М.А. Структурные сдвиги в условиях трансформации экономики России и становления инновационного типа развития: Дисс. д-ра экон. наук: 08.00.01. Томск: ТГУ, 2012. С. 78.

2. Глазьев С. Ю. Мировой экономический кризис как процесс смены технологических укладов // Вопросы экономики. 2009. № 3. С. 26-32.

3. Земсков М.О. Развитие теории структурных сдвигов в экономических системах: автореферат дис.... канд. экон. наук: 08.00.01. Кострома: Костром. гос. ун-т им. Н.А. Некрасова, 2003. 26 с.

4. Красильников О.Ю. Взаимосвязь структурных сдвигов и экономического развития России // Изв. Сарат. унта. Нов. сер. Сер. Экономика. Управление. Право. 2017. № 2. С. 127-133.

5. Львов Д.С. Эффективное управление техническим развитием. М.: Экономика, 1990. 368 с.

6. Маневич В.E. Долговременные макроэкономические процессы и условия роста российской экономики // Вопросы экономики. 2017. № 1. С. 40-63.

7. Минковский Г. Пространство и время. Репринт. М.: Знание, 1991. 226 с.

8. Пелипась И. Реальная, номинальная и институциональная конвергенция в странах ЕАЭС // Рабочий материал Исследовательского центра ИПМ. 2017. WP/17/03. 23 с. URL: http://www.research.by/webroot/delivery/ files/wp2017r03.pdf (дата обращения: 18.06.2019).

9. Питирим Сорокин: Новые материалы к научной биографии. Сб. науч. трудов. / РАН. ИНИОН. Центр социал. науч.-информ. исслед. Отд. социологии и социальной психологии / Отв. ред. Ефременко Д.В., Кротов П.П. М.: Изд-во РАН, 2012. 232 с.

10. Туманова Е.А., Шагас Н.Л. Макроэкономика. Элементы продвинутого подхода. М.: Инфра-М, 2004. С. 201.

11. Яковец Ю.В. Проблемы и перспективы технологического возрождения России // Наука, технология, культура (глобальный процесс и проблемы России): Пробл.-темат. сб. / РАН ИНИОН. Центр научноинформ. исследований по науке, образованию и технологии. Сост. и науч. ред. Ракитов А.И. С. 89-110. URL: https://elibrary. ru/download/elibrary_24243779_18770882.pdf (дата обращения: 18.06.2019).

12. Apergis N., Panopoulou E., Tsoumas C. Old wine in a new bottle: Growth convergence dynamics in the EU // Atlantic Economic Journal. Volume 38. Issue 2. pp. 169-181. URL: https://link.springer.com/content/ pdf/10.1007\%2Fs11293-010-9219-1.pdf (дата обращения: 18.06.2019).

13. Klenow P.J., Rodríguez-Clare A. The Neoclassical Revival in Growth Economics: Has It Gone Too Far? NBER Macroeconomics Annual 1997, Volume 12, ed. Ben S. Bernanke and Julio J. Rotemberg. Cambridge, MA: MIT Press. pp. 73-114. URL: https://www.nber.org/chapters/c11037.pdf (дата обращения: 18.06.2019). 